\title{
TÊMPERA FORTE E COMPLETO DESPRENDIMENTO: HISTÓRIA E MEMÓRIA DAS DOCENTES NO SERTÃO PAULISTA $(1932-1960)^{1}$
}

DOI: http://dx.doi.org/10.1590/2236-3459/72085

\author{
Jorge Luís Mazzeo Mariano' \\ 'Universidade do Oeste Paulista (Unoeste), Presidente Prudente/SP, Brasil
}

\author{
Arilda Ines Miranda Ribeiro" \\ "Universidade Estadual Paulista "Julio de Mesquita Filho" (Unesp), Presidente Prudente/SP, Brasil
}

$\cos 8$

\begin{abstract}
Resumo
O presente artigo exibe a atuação das professoras primárias na construção das bases da cultura escolar frente ao cenário de rudeza e precariedade do extremo oeste paulista, entre as décadas de 1930 e 1960. Para tanto, a pesquisa recorreu à documentação oficial do período e aos relatos orais de algumas docentes que atuaram naquela região. As professoras tiveram que enfrentar as dificuldades inerentes ao início de suas carreiras e de lecionar em imóveis improvisados para a finalidade educativa, como parte de uma espécie de "estágio" na zona rural imposto pelo Estado. Ao lidar com a precariedade das instalações escolares e a presença fiscalizadora do Estado, essas educadoras construíram a cultura escolar das escolas nas quais lecionaram, improvisando com os recursos que possuíam.

Palavras-chave: professoras primárias, extremo oeste paulista, zona rural, escola isolada.
\end{abstract}

\section{CARÁCTER FUERTE Y TOTAL DESAPEGO: HISTORIA Y MEMORIA DE LAS MAESTRAS EN EL SERTÃO PAULISTA (1932-1960)}

\section{Resumen}

En este artículo se muestra el desempeño de las maestras primarias en la construcción de los bases de la cultura de la escuela delante el escenario de rudeza e precariedad de lo extremo oeste de São Paulo, entre los años 1930 y 1960. Por lo tanto, la investigación se dirigió a la documentación oficial de la época y de los relatos orales de algunas maestras que trabajaban en la región. Las maestras tuvieron que hacer frente a las dificultades inherentes al inicio de sus carreras y la enseñanza en edificios improvisados para la finalidad educativa, como parte de una especie de "pasantía" en el campo impuesta por el Estado. Mismo teniendo que manejar con la precariedad de las instalaciones escolares y la presencia de supervisión del estado, estas

\footnotetext{
${ }^{1}$ O presente trabalho se trata de um recorte da tese de doutorado intitulada As influências do trabalho docente feminino na cultura escolar do extremo oeste paulista (1932-1960), defendida no ano de 2016, no âmbito do Programa de Pós-Graduação em Educação da Universidade Estadual Paulista - Unesp (Campus de Presidente Prudente), e contou com o financiamento da Capes.
} 
maestras construyeron la cultura escolar en las escuelas que han enseñado, improvisando con los recursos que tenían.

Palabras clave: maestras primarias, extremo oeste paulista, zona rural, escuela aislada.

\title{
STRONG TEMPER AND COMPLETE DETACHMENT: HISTORY AND MEMORY OF TEACHERS IN THE SERTÃO PAULISTA (1932-1960)
}

\begin{abstract}
This article shows the primary teachers' role in building the foundations of school culture in the face of the rudeness and precariousness of the extreme west of São Paulo, between the 1930s and 1960s. For this purpose, the research resorted to the official documentation of the period and to the oral reports of some teachers who worked in that region. Teachers had to face the difficulties inherent in starting their careers and teaching in improvised real estate for educational purposes, as part of a kind of "internship" in the rural area imposed by the state. In dealing with the precariousness of school facilities and the state's inspection presence, these educators constructed the school culture of the schools in which they taught, improvising with the resources they possessed.

Keywords: primary teachers, extreme west of São Paulo, rural area, isolated school.
\end{abstract}

\section{TREMPE FORT ET COMPLET ABNÉGATION: HISTOIRE ET MEMOIRE DES ENSEIGNANTS EN SERTÃO PAULISTA (1932-1960)}

\section{Résumé}

Cet article montre la performance des enseignants du primaire dans la construction des fondements de la culture de l'école comme scénario brusquerie et précaire de l'extrême ouest de São Paulo, entre les années 1930 et 1960. Par conséquent, la recherche a tourné à la documentation officielle de la période et les récits oraux de certains enseignants qui ont travaillé dans la région. Les enseignants ont dû faire face aux difficultés inhérentes au début de leur carrière et de l'enseignement dans des bâtiments improvisé à des fins éducatives, dans le cadre d'une sorte de "phase" dans la campagne imposée par l'État. Lorsque vous traitez avec la précarité des installations scolaires et la présence de surveillance de l'état, ces enseignants ont construit la culture scolaire dans les écoles ont enseigné, en improvisant avec les ressources dont ils disposaient. Mots-clés: les enseignants du primaire, extrême ouest de São Paulo, zone rural, école isolée. 
[...] quem escolhe cadeira no sertão precisa ter tempera fórte e completo desprendimento.

(RELATÓRIO..., Presidente Prudente, 1941, p. 42)

epígrafe acima foi extraída do Relatório Anual do Delegado de Ensino
referente ao ano de 1940 e resume bem o que se esperava das docentes
que ingressavam no magistério na franja pioneira ${ }^{2}$ da Alta Sorocabana. Procurava-se incutir no imaginário das docentes a representação de que o trabalho que estavam fazendo, assimilava-se ao do bandeirante paulista.

Essa assertiva do Delegado de Ensino referia-se às dificuldades que as docentes enfrentariam no sertão paulista, e encontravam eco nas apropriações destas profissionais: "[...] nossa cidade foi por muito tempo lugar de 'aves de arribação'. Muitos chegavam, mas poucos tinham a fibra necessária para aqui permanecer. Isso observava-se em todos os campos. Comercial, agrícola, educacional e, sobretudo, médico". (D'INCAO, 1982, p. 61).

Desta forma, este artigo pretende exibir a atuação das professoras primárias na construção das bases da cultura escolar frente a esse cenário de rudeza e precariedade do extremo oeste paulista.

\section{As primeiras experiências profissionais na zona rural}

Após concluírem a sua formação como normalistas, as professoras que atuariam na região do extremo oeste paulista passaram por diversas experiências profissionais em outras escolas antes de ingressarem no Grupo Escolar "Dr. Álvaro Coelho" e no Grupo Escolar "Alfredo Westin Júnior"3. Grande parte dessas jovens docentes iniciou a sua vida profissional nas escolas espalhadas pela zona rural.

Cabe ressaltar que a ida de professoras recém-formadas para lecionar na zona rural fazia parte de uma política de Estado que determinava que "o professor deveria começar sua carreira pela escola isolada rural, do interior ou da capital. Só depois de cumprido um determinado tempo poderia ser ele removido para uma escola urbana". (MARCÍLIO, 2005, p. 174-175). Entretanto, tendo em vista que o objetivo era fixar as docentes no campo, essa medida se mostrou ineficaz:

Em termos, essa proposta se mostrou fracassada, pois os professores permaneciam nas escolas primárias rurais apenas durante o período obrigatório e, assim que possível, solicitavam transferência para áreas urbanas ou mais desenvolvidas. E novamente professores novatos involuntários chegavam para dar continuidade a esse ciclo de descontinuidade. (MORAES, 2014, p. 29-30).

Essa transitoriedade também era percebida no extremo oeste paulista. O Relatório da Inspetoria Sanitária de Presidente Prudente indicava que a distância dos grandes centros era um dos motivos pelos quais as/os docentes não permaneciam por muito tempo na região:

\footnotetext{
2 Pierre Monbeig (1984), procurando explicar o avanço em direção ao sertão paulista, menciona as palavras de Isaiah Bowman (1931), que denomina esse tipo de ocupação como sendo uma "franja pioneira". De acordo com o autor, essa franja se trata de uma fronteira que se estende de maneira irregular e sem um direcionamento preciso, promovida por diversos grupos.

${ }^{3}$ A tese de doutorado investigou a atuação das docentes no Grupo Escolar "Dr. Álvaro Coelho" e no Grupo Escolar "Alfredo Westin Júnior" que se localizavam, respectivamente, nos municípios de Presidente Venceslau/SP e Presidente Bernardes/SP.
} 
Pelo facto de estar a zona bastante afastada da Capital e das cidades mais populosas do Estado, todos os elementos que são nomeados para as unidades escolares anceiam por encontrar o momento opportuno para conseguirem remoção para outras localidades onde a vida seja de mais conforto. É por isso que um pequeno número de professores nomeados, poucos se acham exercendo o seu mister, pois que a maioria se encontra comissionada em outra Região. (RELATÓRIO..., Presidente Prudente, 1935, p. 148).

Esse período na zona rural tornava-se uma espécie de estágio para as professoras que lecionariam nos grupos escolares da região, porquanto, em se tratando de cidades no início da colonização, a estrutura física que encontrariam nas escolas primárias graduadas urbanas não seria muito diferente daquela encontrada nos sítios e fazendas.

Zona de estágio, como é esta, não só para o verdadeiro estagiário como para o Diretor do estabelecimento, talvês concorra para o aumento do numero de REPETENTES, por Ihes faltar capacidade tecnica e orientação firmada. (RELATÓRIO..., Presidente Prudente, 1941, p. 12, grifos do autor).

Porém, o Prof. Miguel Omar Barreto, delegado regional do ensino, expressava em seu relatório referente ao ano de 1940, uma perspectiva otimista em relação ao fato de as professoras permanecerem por pouco tempo. No item intitulado "O rendimento escolar: alfabetisação, promoção e o problema dos repetentes", o professor aponta que, não obstante os problemas que as escolas da região enfrentavam, o rendimento dos/das educandos/as havia melhorado sensivelmente e que um dos elementos que contribuíam para isso seria "[...] o grande esforço das professoras, anciosas para regressarem ás zonas onde residem suas famílias". (RELATÓRIO..., Presidente Prudente, 1941, p. 12).

Mesmo com as dificuldades que o sertão apresentava, muitas docentes se estabeleceram na região. Esse é o caso da professora Arthuzina de Oliveira D'Incao, que iniciou a sua carreira na década de 1930, na Associação Escolar Teuto-Brasileira Aymoré, que se situava em um núcleo alemão da cidade de Presidente Venceslau. Ao chegar no município, no ano de 1936, escreveu uma carta a seu irmão, que residia no Rio de Janeiro, descrevendo a suas primeiras impressões acerca de Presidente Venceslau.

A cidade, enfim, é de gênero far-west, com as ruas cheias de areia vermelha e as casas a maioria de madeiras, porém, nada de bandidos barbaçudos e de revólveres nas cinturas; muito pelo contrário, o povo é simples, dado e agradável (já tenho até convite para almoçar numa casa) e as professoras aqui são respeitadas e conceituadas ao extremo. (RIBEIRO, 1936 apud D'INCAO; NASCIMENTO, 2005, p. 114).

Anos depois, a docente relatou, em seu livro Fragmentos (1982), como foi o seu primeiro contato com a localidade na qual iria iniciar a sua carreira no magistério:

Cinco horas da manhã. Tudo muito escuro ainda. Temperatura agradável, mais para fria. Rumor constante de caminhões em movimento. lam para o mato. Uma serraria apitou lá longe...

A cidade despertava.

Sentada contrafeita entre o chofer, um português de barba eriçada, e seu ajudante, um mocinho ainda imberbe, eu seguia para a escola. - Meu primeiro dia de aula! - Assentados ao longo do caminhão despojado de sua carroceria, com as pernas bamboleando para fora, homens mal vestidos, barbudos, esquisitos. (D'INCAO, 1982, p. 94-95). 
As condições precárias do transporte ${ }^{4}$ e das estradas eram questões que as autoridades do ensino apontavam como fatores que desmotivavam a permanência das professoras na zona rural. Almeida Junior, no Anuário do Ensino do Estado de São Paulo (1936), ressalta que "Quasi sempre é a facilidade de acesso que enseja a escola. Estradas que facilitem a viagem do professor, do alumno e do inspector; que evitem áquelle a sensação deprimente de segregação [...]". (SÃO PAULO, 1936, p. 195). E foi exatamente nesse contexto e nessas condições que Arthuzina D'Incao chegou à zona rural de Presidente Venceslau: "Curiosa estrada aquela! - Estreita; dois caminhões não poderiam passar; de distância em distância, simulacros de desvios. O caminhão andava com dificuldade por dois sulcos abertos no terreno arenoso". (D'INCAO, 1982, p. 95).

De certo modo, as professoras já tinham um conhecimento prévio das condições que encontrariam no oeste paulista. Isto porque as representações que circulavam na sociedade, associadas ao aprendizado recebido nas Escolas Normais, indicavam os riscos e os desafios que o sertão paulista apresentava: "No mapa ilustrado, um grupo de árvores dentre as quais onças 'espiavam' meia dúzia de índios em torno de uma fogueira. — Esse o meu primeiro contato com Presidente Venceslau, quando ingressei no magistério". (D'INCAO, 1982, p. 76).

Entretanto, malgrado a hostilidade atribuída à região, Arthuzina - assim como as outras docentes que partiram para o extremo oeste paulista, movidas pela necessidade financeira, ou mesmo pelo desejo de exercer o magistério - permaneceu: "Pensam que me assustei? - Não. Era muito jovem. Não tinha medo. Pelo contrário, muita coragem e uma vontade indômita de descobrir o mundo". (D'INCAO, 1982, p. 76).

Porém, mesmo afirmando a sua coragem, a docente, assim como ocorria com grande parte das profissionais que se deslocavam para a região, não planejava continuar no sertão. Arthuzina descreve na referida missiva enviada a seu irmão, o que pretendia fazer no ano seguinte à sua chegada:

E assim, estou muito bem instalada, no meio de várias collégas de exilio. E na casa de uma bôa senhóra.

E assim até o fim do anno passarei, se Deus quizér, minha vidinha aqui; depois ou prestarei concurso para a escola de aperfeiçoamento ou então de remoção. (D'INCAO, 1936 apud D'INCAO; NASCIMENTO, 2005, p. 114).

Além da representação de rudeza imputada à região e da sensação de se encontrar exilada, a professora que acreditava que as mulheres da localidade ainda tinham o seu campo de atuação muito restrito ao âmbito doméstico, surpreendeu-se com a presença de uma mulher: "- Impressionou-me logo ao chegar, o vulto tranquilo de uma farmacêutica5", atendendo à única farmácia local. - 'Farmácia Popular, a farmácia de Confiança', era o seu slogan". (D'INCAO, 1982, p. 76). Despertava a atenção da professora, em terras tão longínquas e, por isso, associadas ao primitivo ${ }^{6}$, que uma farmácia, "[...] numa época em

\footnotetext{
${ }^{4}$ Ainda sobre os transportes, Arthuzina fornece mais um relato: "E rememoro os desconfortáveis meios de transporte que a cidade de ontem oferecia às valorosas mocinhas, que para cá vieram alicerçar a mente de nossa gente. Variava da mula russa e manhosa à aranha ou charrete e, sobretudo, aos caminhões de toros. Acredito que esses hajam sido mesmo o meio de transporte mais usado". (D'INCAO, 1982, p. 99).

${ }^{5} \mathrm{~A}$ farmacêutica em questão era Marfiza D'Incao, que veio a se tornar cunhada de Arthuzina quando esta se casou com Mânlio D'Incao, no ano de 1937.

${ }^{6}$ Romanello (1998, p. 73) ressalta que "esta imagem de uma parte do Oeste Paulista em muito se aproxima da atribuição genérica de Sertão, a terra ocupou assim no momento dos 'primeiros contatos', a condição de
} 
que a atuação feminina (exceção feita às professoras) ainda se restringia ao âmbito doméstico, [tivesse] a sua frente o vulto gentil de uma mulher". (D'INCAO, 1982, p. 76, acréscimo nosso).

Além do fato de existir uma farmacêutica trabalhando em Presidente Venceslau, na década de 1930, é interessante observar o cuidado que a Arthuzina possui ao excluir as professoras do grupo oprimido. Isto mostra o quanto o trabalho das feministas havia ecoado e atingido as mulheres, a ponto de a referida docente não se enxergar dentro do esquema de opressão que ligava as mulheres à esfera doméstica - mesmo que o magistério feminino ainda estivesse imbuído dessas mesmas concepções ${ }^{7}$.

Muito embora o magistério feminino fosse revestido de uma ideologia que o ligava à maternidade, a docência foi uma das primeiras profissões que as mulheres tiveram acesso e que permitiu, portanto, que elas se afastassem (ainda que de modo controlado) da esfera doméstica. Como afirma Almeida (1998, p. 75), "o magistério primário representou o ponto de partida e o que foi possível no momento histórico vivido", e o fato de Arthuzina ter encontrado uma farmacêutica é indicativo do processo de desenvolvimento profissional feminino, isto porque "[...] logo depois de terem ocupado o magistério primário, as mulheres conseguiram acesso ao secundário e puderam frequentar as universidades, e, paulatinamente, foram dirigindo-se para outras profissões". (ALMEIDA, 1998, p. 75).

Portanto, como Arthuzina entendia que as professoras, ao contrário da maioria das mulheres da época, não estavam presas à esfera doméstica, e tendo encontrado uma mulher exercendo uma profissão remunerada - que, tal como a carreira docente, exigia um determinado nível de escolaridade -, a sua percepção acerca da região começou a se alterar. A figura da farmacêutica, descortinou novas possibilidades de ação, fazendo com que a professora identificasse um ambiente no qual as mulheres poderiam trabalhar e se desenvolver, mesmo com todas as dificuldades apresentadas pela estrutura deficitária do município: "Mas voltando à farmacêutica, ela foi para mim o cartão de visitas da cidade. Fez-me bem. Amenizou minha chegada. - Não poderia ser rude, muito menos selvagem, uma cidade franqueada aos já então discutidos direitos femininos”. (D'INCAO, 1982, p. 77).

Ademais, Arthuzina relata a chegada de mais uma mulher de atuação destacada no município de Presidente Venceslau: Isabel de Campos $^{8}$.

Mais tarde, com a elevação de Presidente Venceslau à comarca, chegou-nos uma advogada. A primeira a se iniciar na vida forense local. — De início objeto de muitas críticas pela linha conservadora dos "machões" (perdoem-me a franqueza, se ainda

lugar inóspito e selvagem, a ser dominado. Visões de progresso e evolução, tornam-se conceitos indissociáveis, ligados diretamente ao domínio e avanço da vontade humana sobre a natureza e sobre a inépcia do Estado em promovê-las".

${ }^{7}$ Louro (1997, p. 88) questiona qual seria o gênero da educação e exibe uma representação recorrente acerca do trabalho docente feminino: "[...] os discursos pedagógicos (as teorias, a legislação, a normatização) buscam demonstrar que as relações e as práticas escolares devem se aproximar das relações familiares, devem estar embasadas em afeto e confiança, devem conquistar a adesão e o engajamento dos/as estudantes em seu próprio processo de formação. Em tais relações e práticas, a ação das agentes educativas deve guardar, pois, semelhanças com a ação das mulheres no lar, como educadoras de crianças ou adolescentes".

8 "Isabel de Campos nasceu no Rio de Janeiro, no dia 23 de maio de 1889. [...] Já passava dos trinta anos de idade, quando ingressou na tradicional Faculdade do Largo São Francisco, onde colou grau em direito, no mês de dezembro de 1936. Formada, veio, no começo do ano de 1937, tentar a sorte, neste rincão paulista, onde montou banca de advogada. O então Prefeito Nicolino Rondó a nomeou assistente jurídica da Prefeitura Municipal. [...] Faleceu em 14 de maio de 1972". (ERBELLA, 2006, p. 548-549). 
os há por esta terra!), não tardou a sem impor. Aqui permaneceu até morrer. Hoje dá nome a uma de nossas escolas: Escola Estadual de Primeiro Grau "Dra. Isabel de Campos". Homenagem merecida. (D'INCAO, 1982, p. 77).

Como é possível notar, apesar da distância que separava a região da Alta Sorocabana dos grandes centros populacionais, algumas figuras femininas já despontavam e apresentavam uma atuação distinta do enquadramento normativo à qual estavam submetidas na sociedade.

Ainda na década de 1930, chegou à região a professora Maria de Nazareth Miméssi Gonçalves. Esta professora também realizou as suas primeiras experiências no magistério, na zona rural de Presidente Bernardes, a partir do ano de 1937.

Wanda Pereira Morad chegou a Presidente Venceslau no ano de 1942 e começou a lecionar em uma fazenda e, nos quatro anos subsequentes, em mais quatro escolas isoladas. No período em que lecionou na zona rural de Presidente Venceslau, a referida professora também contribuía com o projeto nacionalista de Vargas, mediante a exaltação dos símbolos pátrios:

Eu ensinava as meninas e os meninos do sítio a cantar o Hino Nacional, o Hino à Bandeira, o Hino da Independência, eu cantava, eu sempre cantei - por isso que eu estou perdendo a voz - aí era uma maravilha! Eles cantavam com amor, colocavam a bandeira, todo mundo batia palma. Hoje eu não vejo nada. Quem vai lá puxar a bandeira é um empregado de prefeitura e pronto, e que se dane. (MORAD, 2013).

É possível perceber na fala da docente, além de sua apropriação das práticas incentivadas pela política fascista do Estado Novo, como o mecanismo da rememoração atua. Isto porque, somado ao fato de Wanda ter compreendido o ato de cantar os hinos com as/os discentes como uma prática positiva, existe ainda a questão da supervalorização do passado, uma vez que no relato das pessoas idosas as memórias da infância e da juventude aparecem frequentemente dulcificadas.

É muito comum que se encontre um conflito entre valores gerais que se acredita serem verdadeiros no passado e o registro mais preciso sobre a vida do dia-a-dia; essa contradição, porém, será por si só extremamente reveladora, pois pode representar uma das dinâmicas da mudança social. (THOMPSON, 1992, p. 305306).

No decorrer da década de 1940, começaram a chegar mais professoras para lecionarem nas escolas rurais da última franja pioneira do Estado. Esse foi o caso de Maria Apparecida Lotto de Olyveira, que chegou à zona rural de Presidente Bernardes, no ano de 1947. Na narrativa da docente, é possível notar a representação que ainda se tinha da região quase na metade do século XX: "Eu fui reto, hein. Depressa. E fui para o mato. Aqui era considerado sertão". (OLYVEIRA, 2013).

Primeiramente, a professora exibe em sua narrativa o choque entre a vida urbana que levava na cidade de Jaú/SP, e o trabalho que deveria executar a mais de $300 \mathrm{~km}$ de sua terra natal, na zona rural de Presidente Bernardes/SP.

Eu me lembro de quando cheguei aqui [em Presidente Bernardes/SP], peguei um táxi e aí, eu tenho uma foto, não sei onde está, eu estou com um turbante, um tailleur, aí vai para a fazenda. Cheguei aqui no Grupo e me apresentei, aí quando eu vi, peguei o táxi, e ele me levou lá [na fazenda]. 
Eu era da igreja [católica], participava de tudo, era Filha de Maria, da JEC ${ }^{9}$, cantava no coro. Eu tenho uma foto da despedida de minhas amigas na porta da igreja. Nós todas estávamos ali e eu ia embora para a roça. Eu estava com um turbante bonito e um tailleur para ir para a roça! (OLYVEIRA, 2013, acréscimos nossos).

Maria A. L. de Olyveira realizou os seus estudos em um tradicional colégio religioso e, além disso, residia na casa de sua avó que era proprietária de um hotel. Portanto, depreende-se que a docente vivia em uma situação econômica confortável, o que the proporcionou todo o suporte e tranquilidade para a realização de sua formação e, outrossim, a possibilidade de continuar na região. Todavia, a professora decidiu se mudar, mesmo desconhecendo Presidente Bernardes. Questionada sobre os motivos que a levaram a optar pelo "sertão", a docente explanou:

[...] eles falavam: a senhora está louca? Ir pra lá!? Lá é lugar em que o delegado tem muito serviço... A senhora vai para o mato! Deram contra. Era essa vaga, teve uma desistência e eu escolhi com ponto de diploma, menino. Aí falei: "Não, ninguém me tira. Eu vou!". (OLYVEIRA, 2013, acréscimos nossos).

Um elemento de destaque em sua fala é a representação de que a região da Alta Sorocabana era violenta. A imagem das disputas pela terra por posseiros, grileiros e fazendeiros que se deslocaram para a última franja pioneira do Estado de São Paulo no início do século XX, ainda estava presente nas décadas que se seguiram, refletindo-se nos alertas que foram dados à professora Maria A. L. de Olyveira ('Lá é lugar em que o delegado tem muito serviço... A senhora vai para o mato!')

Historicamente, a concepção de "sertão" está eivada de significados, remontando a colonização do país, ora sendo representado pelos portugueses como o inferno, ora como paraíso. 'Variando segundo a posição espacial e social do enunciante, 'sertão' pode ter significados tão amplos, diversos e aparentemente antagônicos". (AMADO, 1995, p. 149).

Os indivíduos que se deslocavam para a região e nela se estabeleciam, ou mesmo que nela nasceram, possuíam muitas vezes representações positivas sobre a vida na Alta Sorocabana. Após a chegada da ferrovia e o desenvolvimento dos municípios cada vez mais sujeitos chegavam ao extremo oeste paulista, o que contribuiu para o seu rápido progresso e apesar das dificuldades inerentes aos primeiros anos, as pessoas alóctones criavam laços afetivos e de trabalho com a localidade, passando a representá-la de um modo distinto ao pensamento corrente.

Eu fui reconhecida [como professora em Presidente Bernardes]. Meu lugar é aqui. Casei, fiquei e estou aqui até hoje. Criei os meus seis filhos.

Para você ver, as minhas irmãs: uma foi para Bauru/SP, outra foi para Ribeirão Preto/SP e a Doca veio para o mato. (Risos). Encontrei tanta gente boa. (OLYVEIRA, 2013).

A docente relatou as dificuldades dos primeiros anos e o seu primeiro contato com a zona rural:

Cheguei aqui, menino, a escola era de madeira, eu tinha que ir à cavalo, não tinha carro - existiam apenas dois taxis na cidade - e eu fui pra lá. [Usava-se] lamparina na casa em que eu morava [...]. A escola que eu falei para você era de tábua,

${ }_{9}$ A Juventude Estudantil Católica (JEC) surgiu em 1935, no contexto da criação da Ação Católica Brasileira (ACB). 
passava barro no chão, para ficar bonito, e [a iluminação] era à lamparina. (OLYVEIRA, 2013, acréscimos nossos).

Onze anos antes de a professora chegar à Presidente Bernardes a questão das instalações nas quais as professoras habitavam já era motivo de preocupação para as autoridades estaduais da educação: "Dão-Ihe uma tulha velha ou uma sala pequena e antihygienica, para as suas aulas. Arranjam-lhe pensão em casa de sitiante que desconhece as condições mais elementares de conforto". (SÃO PAULO, 1936, p. 182). Ademais, como a região ainda carecia de transportes, o deslocamento das professoras entre a cidade e a zona rural era feito, como já mencionado, por caminhões de toras ou em lombos de cavalos.

Tal como Maria A. L. de Olyveira, Thereza de Camargo Vieira também chegou à Presidente Bernardes no final da década de 1940, hospedando-se, inclusive, na mesma pensão. Outra semelhança entre a professora Maria A. L. de Olyveira e a professora Thereza, além de terem iniciado a sua carreira na zona rural de Presidente Bernardes e de terem residido na mesma pensão (e, mais adiante, trabalharam e se aposentaram no Grupo Escolar "Alfredo Westin Junior"), é o fato de chegarem à região acompanhadas de uma tia:

[...] eu vim com uma tia minha. Ela veio para trabalhar também e para me fazer companhia, porque naqueles anos o pai não deixava a filha sair para longe, ainda mais aqui que era o fim do mundo. [...] Ela veio comigo e foi a minha companheira, nós viemos juntas porque [senão] meu pai não deixava: - Ah, a minha filha não vai longe. Filha minha vai ficar aqui! (VIEIRA, 2013, acréscimos nossos).

Um elemento a se observar no relato de Thereza é a questão do gênero, pois mesmo necessitando de trabalhar, o pai da docente somente permitiu que ela se deslocasse $474 \mathrm{Km}$ de sua casa, se tivesse a companhia de uma parente. Postura que remonta uma tradição lusitana - transposta para a realidade brasileira - na qual as mulheres viviam reclusas na esfera doméstica, o que era atestado por alguns estrangeiros que visitavam o país, como é o caso do inglês "Luccock, viajante do século XIX, que observou que a reclusão feminina ainda predominava nessa época, afirmando que as mulheres portuguesas raramente saíam de casa" (RIBEIRO, 2007, p. 83), certamente se referindo àquelas provenientes das elites.

Próximo à metade do século $\mathrm{XX}$, um resquício dessa postura ainda se fazia presente expressa aqui no excessivo controle do pai de Thereza procurando direcionar onde a filha deveria ir - de preferência não muito distante. Todavia, é notável a atualização desse ideário patriarcal, haja vista que a docente não era de uma família abastada, portanto, necessitaria trabalhar para o seu sustento e para ajudar as suas irmãs a estudar. Além disso, sinal dos tempos, não foi o seu pai quem the acompanhou até a Presidente Bernardes, mas uma outra mulher, sua tia, legitimando o protagonismo feminino.

De acordo com o relato de Thereza, essa tia que a acompanhou também trabalhou na zona rural como professora leiga. $O$ fato de existirem professoras leigas lecionando na região era reconhecido como um problema pelos dirigentes estaduais da educação, que, em 1940, já alertavam para os reflexos dessa questão no rendimento escolar das crianças:

O rendimento escolar de nossa REGIÃO, a despeito de muitas escolas vagas, regidas por leigas, pouco competentes e de várias outras que permaneceram fechadas por falta absoluta de substitutas, têm melhorado sensivelmente. (RELATÓRIO..., Presidente Prudente, 1941, p. 12, grifos do autor). 
Assim, no início da década de 1950, mais docentes chegavam à Alta Sorocabana. Maura Pereira Estrela concluiu a sua formação como normalista na cidade de Tatuí/SP em 1949 e, ao contrário de Thereza, foi incentivada a se mudar para longe: "A minha mãe era bem moderna! Ela dizia que nós tínhamos que trabalhar e lá não tinha aula para todo mundo. Então aquelas que tinham pai ainda - nós não tínhamos pai - ficavam". (ESTRELA, 2013).

No ano seguinte da formatura de Maura, a sua irmã Wanda, que já se encontrava em Presidente Venceslau há sete anos, encaminhou-a à região oeste.

\begin{abstract}
A minha irmã [Wanda Pereira Morad] veio primeiro e se casou aqui, começou a trabalhar, ela tinha sete anos a mais do que eu, [ficou] lecionando na redondeza. Aí ela me trouxe quando eu terminei o [curso na Escola] Normal, para dar aulas aqui. Foi no ano de 1950, fevereiro de 1950. [...]. Foram dois anos assim: 1950, 1951 e 1952. Em maio de 1952 eu me efetivei, eu fiquei na Madeiral por dois anos, e quando foi para eu casar, em 1954, já me removi para a cidade, para o [Grupo Escolar] Dr. Álvaro Coelho. (ESTRELA, 2013, acréscimos nossos).
\end{abstract}

Nesse período, a docente lecionou primeiramente como professora substituta e de 1952 a 1954 como professora efetiva, mas sempre na zona rural de Presidente Venceslau.

Uma peculiaridade presente no relato de Maura e também das demais docentes, refere-se ao fato de que estas necessitavam se deslocar para os sítios em caminhões de toras, que eram muito comuns na região em função da intensa atividade das serrarias. Contudo, a referida docente ressaltou um ponto não destacado pelas demais professoras, qual seja, o assédio sofrido. Isto porque os trabalhadores que partiam para o desmatamento, ao ajudarem as jovens docentes fornecendo-lhes o transporte, não deixavam de importuná-las: "Então nós íamos de calça comprida para subir, mulher né? A gente viveu só de carona, você nem sabe! Pedi carona de caminhão, os caminhoneiros muitas vezes mexiam com a gente. Não chegavam a assediar, falavam umas bobagens". (ESTRELA, 2013, acréscimos nossos).

Os mecanismos de submissão pelos quais as mulheres estiveram historicamente sujeitas estavam enraizados de tal forma que a professora não chegava a considerar os gracejos dos caminhoneiros como sendo um tipo de ofensa ou de invasão de sua privacidade. Neste sentido, Bourdieu (2011), ao discutir a questão da dominação exercida pelos homens, a enquadrava como sendo um tipo de violência simbólica:

[...] sempre vi na dominação masculina, e no modo como é imposta e vivenciada, o exemplo por excelência desta submissão paradoxal, resultante daquilo que eu chamo de violência simbólica, violência suave, insensível, invisível a suas próprias vítimas, que se exerce essencialmente pelas vias puramente simbólicas da comunicação, ou, mais precisamente, do desconhecimento, do reconhecimento ou, em última instância, do sentimento. (BOURDIEU, 2011, p. 7-8).

Além disso, havia o fato de ela não poder utilizar calças no ambiente de trabalho, que foi um aspecto observado pela maioria das entrevistadas: "Não podia! Na escola não podia! Era só nesse lugar, a gente levava a saia na bolsa e colocávamos lá [na escola]". (ESTRELA, 2013, acréscimos nossos). Deste modo, é válido mencionar que essa postura calcada em princípios religiosos, encontrava respaldo na sociedade que contribuía para disseminar essa representação acerca das vestimentas "adequadas" para cada gênero.

Um exemplo desse posicionamento pode ser encontrado no jornal "A Tribuna" de 
Presidente Venceslau, em sua edição de 29 de agosto de 1954, na qual o articulista denominado Rocha Camargo escreve um texto comentando uma pastoral escrita por D. José Maurício da Rocha, então Bispo de Bragança Paulista/SP. Na referida pastoral, D. José baseia-se no Antigo Testamento da Bíblia para proibir às mulheres católicas de sua cidade o uso de "calças masculinas", visando "[...] enfrentar diretamente a situação, que está tomando proporções alarmantes nesta cidade e em outras paróquias da diocese, com a quebra das nobres tradições da família bragantina e paulista". (ROCHA apud CAMARGO, 1954, p. 2). Na sequência, o Bispo descreve as sanções às mulheres que utilizassem calças:

[...] somos forçados, pois, a determinar que sejam excluídas da recepção de sacramentos, até que se emendem, não podendo tambem servir de madrinhas de batismo, de crisma e de casamentos, todas as mulheres, de qualquer estado ou condição, que, afrontando a proibição divina e estas nossas determinações, continuarem a usar calças masculinas, e a moda de homens, ou virem a usa-las nas ruas, passeios, etc., excetuadas as montarias em viagens a cavalo, tanto mais porque não ha necessidade de tal uso, nada havendo o que justifique senão a insensatez dos que o inculcam. [...] Em iguais penas incorrem as mães que permitem às suas filhas, mesmo pequenas, tal uso, pois acostumadas desde crianças, com maioria de razão irão faze-lo quando crescidas. (ROCHA, 1954 apud CAMARGO, 1954, p. 2).

Com essa postura antimodernista ${ }^{10}$ adotada pela Igreja Católica, as restrições historicamente construídas para as mulheres davam sinais de continuidade em meados do século $X X$, especialmente se considerarmos que no texto o clérigo estende a proibição também às meninas.

Rocha Camargo endossa a postura de D. José ao afirmar: "Aí fica, pois, o protesto clerical contra o USO de nossas venerandas calças". (CAMARGO, 1954, p. 2, grifos do autor). Não obstante essa proibição não atingir às mulheres de Presidente Venceslau, o articulista se apropriou da representação veiculada pelo Bispo aproveitando para expressar a sua compreensão do texto.

O feminismo, - "conjunto de princípios que preconizam a igualdade dos direitos da mulher e do homem, especialmente na vida civil e política" - pouco difére, segundo essa definição, do sufragismo, que tanto empolgou, em certa época, as mulheres inglezas, pondo mesmo em risco a integridade física masculina. Este último movimento feminista, todavia, se bem que tenha sido, naquele tempo, apenas um debate visando futuras reivindicações, foi promovido unicamente por certa categoria de mulheres deslocadas de seu verdadeiro ambiente, - o Lar, - mulheres solteironas, fisicamente desvantajosas e temivelmente feias! (CAMARGO, 1954, p. 2, grifos nossos).

O autor desviou-se do tema central da pastoral, para atacar explicitamente as mulheres. Como se a proibição da utilização das calças pelas mulheres já não fosse um tema suficientemente polêmico, Rocha Camargo resolveu ir além, realizando uma crítica infundada ao movimento feminista que naquela época sofria um refluxo em suas atividades

$10 \mathrm{O}$ antimodernismo que se expressa nas palavras de D. José Maurício da Rocha remonta a uma história antiga de embate entre a Igreja Católica e a modernidade: "[...] A autoridade, constituída de acordo com a concepção da Igreja, encontraria diversas ameaças no convívio com a cultura moderna, uma vez que ela é vista como provocadora de rupturas e estimuladora da emancipação dos indivíduos e da sociedade. [...] Sendo a 'síntese de todas as heresias', o modernismo era considerado uma reunião de todas as ameaças: a aberração do entendimento, o amor às novidades e o orgulho". (DIAS, 1996, passim). 
no Brasil ${ }^{11}$. Alude a um suposto risco que os homens teriam sofrido com as manifestações das mulheres para, em seguida, afirmar que o lugar destas era o espaço doméstico e partir para uma sequência de ataques à aparência física das feministas. Assim, é notável o incômodo que a ação do movimento feminista causava em alguns homens, que, sentindose ameaçados, criavam uma celeuma provavelmente com o intuito de forjar uma representação, acreditando que as discussões acerca dos direitos femininos não tivessem chegado em plagas tão distantes quanto às do extremo sudoeste paulista.

Daí para cá tal movimento se generalizou, com pequenas variações de princípios, e sob novo lema, no sentido de completa emancipação da mulher, - que deseja, como aliás sempre desejou mas não pôde, - eximir-se do pátrio poder quando menor, e quando maior e casada, da tutela marital. Aí está uma das razões por que o casamento, atualmente, é uma temeridade por parte do homem, e, quando se atreve a esse arrôjo, em breve terá ele que procurar uma brécha escapatória no divórcio ou no desquite. E o que vemos aí está: - essa desnorteante inversão na ordem natural das revelações humanas. (CAMARGO, 1954, p. 2).

Com este último trecho, Camargo exibe o seu menosprezo pelas conquistas das mulheres, numa clara tentativa de desqualificar as lutas do feminismo. Como o jornal era um dos poucos meios de comunicação da cidade na época, os textos nele publicados possuíam uma grande relevância uma vez que atingiam o público alfabetizado e tanto as ideias transmitidas por Rocha Camargo quanto as restrições morais veiculadas pela Igreja católica repercutiam na sociedade.

Essas posições eram disseminadas e apropriadas pela população das mais diferentes formas, e, como objetivavam explicitamente moldar a ação das mulheres, as professoras sentiram os efeitos:

Eles não aceitavam professora [nas pensões]! Professora tinha o nome meio sujo por causa de algumas professoras que faziam umas "artinhas" [...]. O pai do professor Abílio, o português que tinha uma pensão em frente ao posto, eu meu lembro tão bem que eu fui lá e disse que precisava [de um quarto] [...] e ele falou na minha cara: Você é professora? Aqui no meu estabelecimento não entra professora! [...]. (ESTRELA, 2013, acréscimos nossos).

Além da questão de gênero que as professoras tinham que lidar no cotidiano, havia ainda, como já mencionado, o problema recorrente das instalações que receberiam as docentes, uma questão que se manteve na década de 1950, assim como atesta Maura em seu relato:

E lá no [sítio] São Benedito em morei em casa de barro. Era um perigo não só por causa dos escorpiões como também pelos barbeiros. Eu tinha amizade com as moças que moravam nas casas, as filhas do casal dormiam no mesmo quarto, todas as semanas elas barreavam as casas, todas as paredes, para não criar barbeiro [...]. (ESTRELA, 2013, acréscimos nossos).

Essa situação enfrentada por Maura nas duas primeiras escolas em que lecionou, se assemelha muito ao que Almeida Júnior denunciava em seu relatório em 1936, evidenciando que apesar das recomendações das autoridades, a situação da educação na

\footnotetext{
11 Pinto $(2003$, p. 10) assevera que existiu um hiato nas atividades do movimento feminista brasileiro no "[...] longo período que se estende de 1932 até as primeiras manifestações nos anos de 1970. Este foi um período de refluxo do movimento feminista".
} 
zonal rural pouco se alterou na Alta Sorocabana.

Quanto menor e mais atrazado o núcleo escolar, tanto maior a dependencia em que fica a professora. A sala de aula é obtida por favor especialissimo, e á custa da propria moça. Tambem o alojamento e a pensão. A condução tem que ser pleiteada. [...] Arrancha-se a moça na casa do caipira. A dona de casa, embora excellente pessoa, cozinha mal o seu feijão sem gordura; desconhece o asseio; pita e cospe o dia inteiro, para todos os lados. Destinam á professora um quarto esburacado, tambem deposito de arreios (Estou reproduzindo um quadro real, que se repete, com variante). Agua difficil; ausencia de installações sanitarias. (SÃO PAULO, 1936, p. 196).

Além da precariedade da estrutura física dos prédios, havia também a questão dos materiais escolares que ou não eram oferecidos ou, quando existiam, eram em quantidade insuficiente. O que de certo modo representava uma espécie de estágio para as professoras, já que com essa experiência puderam aprender a se desdobrarem com o pouco que era oferecido pelo Estado - realidade com a qual se defrontariam também nos grupos escolares.

Eles davam um pouco de material. Muito pouco, faltava tudo. Eram aqueles caderninhos de linguagem que eles davam, dez desses, aí você via a criança que era mais pobrezinha e nós dávamos. E não podia ter milhares de cadernos, a gente ia só naquele caderninho, fazia tudo ali, economizando papel. O professor comprava muita coisa!... A gente completava o que ganhava da escola, indo na livraria e comprando com o dinheiro de gente. Giz, nós comprávamos. (ESTRELA, 2013).

As práticas escolares levadas a cabo pelas docentes para contornarem as restrições impostas pela conjuntura, denotam como a cultura escolar era construída e, neste caso, com a tentativa de se ajustar à localidade. Julia (2001) alerta para a necessidade de se pensar a cultura escolar na trama das demais culturas coetâneas com as quais estabelece relações amistosas ou conflituosas ${ }^{12}$. Especificamente sobre a cultura escolar, o autor francês ressalta que as normas e práticas são os elementos a se atentar para a uma análise dessa natureza, não secundarizando, obviamente, a atuação dos/das profissionais que estão submetidos/as a essas normas e que as põem em prática.

O empenho com que Maura buscava lidar com as dificuldades apresentadas pelo cotidiano escolar, contribuía também na construção de uma imagem ideal das professoras. Era corrente a representação criada em torno da figura da docente, como aquela pessoa abnegada, que tinha a missão de levar o magistério até mesmo aos sertões mais longínquos. Entretanto, não escapava à percepção dessas profissionais como era gestado todo esse respeito que os sitiantes e os colonos possuíam, como afirma Maura:

Eles respeitavam muito a gente, a professora era adorada na escola. A melhor comida era para a professora, comíamos primeiro, eles arrumavam a mesinha. $O$ Sr. Adamastor também trabalhava muito essa parte: antes da professora ir [para o sítio] ele falava com a pessoa mais importante do bairro, falando que eles tinham que dar um lugar ótimo para as professoras, porque senão a professora não fica,

\footnotetext{
12 Essa interação mostra que a cultura escolar é influenciada e também influencia as culturas que com as quais convive, pois, "[...] para além dos limites da escola, pode-se buscar identificar, em um sentido mais amplo, modos de pensar e de agir largamente difundidos no interior de nossas sociedades, modos que não concebem a aquisição de conhecimentos e de habilidades senão por intermédio de processos formais de escolarização: aqui se encontra a escalada dos dispositivos propostos pela schooled society que seria preciso analisar". (JULIA, 2001, p. 11).
} 
eu não deixo! Por isso que nós éramos muito bem tratadas. (ESTRELA, 2013, acréscimos nossos).

Esse trecho contribui para aclarar a noção de que as representações são práticas culturais, isto é, formas de pensar e construir a realidade. De acordo com Roger Chartier (2002, p. 17), essas formas de pensar são socialmente forjadas e:

[...] não são de forma alguma discursos neutros: produzem estratégias e práticas (sociais, escolares, políticas) que tendem a impor uma autoridade à custa de outras, por elas menosprezadas, a legitimar um projeto reformador ou a justificar, para os próprios indivíduos, as suas escolhas e condutas.

Desse modo, o Sr. Adamastor de Carvalho, revestia-se do poder que o seu cargo de diretor do Grupo Escolar de Presidente Venceslau Ihe concedia, para disseminar uma representação que exercia duplo efeito naquela ocasião específica: por um lado fazia com que a população da zona rural aclamasse a vinda daquela professora como uma espécie de dádiva que poderia ser retirada a qualquer momento ("porque senão a professora não fica, eu não deixo!") caso a docente fosse mal tratada; e por outro lado, ajudava a construir na professora a consciência de sua importância para aquela escola.

Fica evidente nesse caso também o jogo de poder que está envolvido na construção e/ou reforço das representações, pois através destas "um grupo impõe, ou tenta impor, a sua concepção do mundo social, os valores que são os seus, e o seu domínio" (CHARTIER, 2002, p. 17), tal como fez o diretor do grupo, não de maneira individualizada, mas enquadrado dentro de uma estrutura estatal e burocrática que Ihe incumbia essa função.

Contudo, mesmo com toda a força que as representações exerciam sobre as professoras e sobre os/as educandos/as, existem as apropriações que são próprias de cada grupo. A apropriação é a "forma pela qual os indivíduos reinterpretam e utilizam-se de modelos culturais impostos e em circulação em um determinado momento" (SOUZA, 2000, p. 6) e, sendo assim, mesmo tendo sido criada uma aura de respeitabilidade à figura da docente que era fomentada pelo Estado, reforçada pelo diretor, e voltada para o convencimento da professora, esta não se mostrava alienada de todo esse processo ("Por isso que nós éramos muito bem tratadas").

Adamastor de Carvalho desempenhava as suas funções de diretor de forma rígida e às vezes invasiva, como transparece no relato da docente, que demonstrou se sentir incomodada com a vigilância exercida sobre as docentes que lecionavam na zona rural:

Uma outra coisa [era] que ele pegava muito [no pé de] todas as professoras do sítio... Não era uma ou duas professoras, eram todas! Quando a gente vinha para a reunião, no primeiro sábado do mês era a reunião, como era muito longe nós vínhamos na sexta-feira. E ele queria que nós voltássemos no domingo! A coisa mais difícil era encontrar condução no domingo! Ele falava na reunião: "Eu não quero nem saber! Vocês tem que ir embora no domingo para poder dar aula na segunda de manhã!" [...]. (ESTRELA, 2013, acréscimos nossos).

Todavia, desde os tempos em que lecionavam nos sítios, as professoras já desenvolviam as suas estratégias para lidar com as exigências burocráticas. Neste caso, diante da impossibilidade de se cumprir com a imposição disciplinar exigida pelo diretor, Maura descreve como procedia para conseguir chegar ao sítio na segunda feira, sem, 
contudo, seguir o roteiro estabelecido:

Então a gente o enganava, nós éramos novas e tudo... Então muitas vezes eu ia até Caiuá/SP, ficava na pensão, que era gente muito conhecida minha de Tatuí/SP, e ficava lá para na segunda-feira ir embora. Ele muitas vezes não ficava sabendo, mas sempre tinha alguém que dedava. [...] Era assim, eles exigiam muito de nós, muito mesmo! E eu o mês inteiro no sítio, não deixava vir. Vinha escondida no cinema para ele não ver. (ESTRELA, 2013).

Em 1952, chegava à Presidente Venceslau uma docente que viria a se tornar uma grande amiga de Maura, trata-se de Maria Therezinha de Granville Ponce Carvalheiro. Assim como sua amiga, Maria Therezinha iniciou a sua carreira na zona rural do município.

Maria Therezinha provinha de uma situação confortável, tanto na questão financeira, quanto na estrutura oferecida pela cidade em que residia (Pirajuí/SP). Neste sentido, a docente exibiu as primeiras impressões que teve ao chegar à Presidente Venceslau e se defrontar com uma realidade completamente distinta da qual estava habituada.

No dia em que cheguei foi um espanto, porque em Presidente Venceslau/SP era uma "coisica", não tinha nem calçada, as calçadas eram de madeira, os boiadeiros andavam com aquelas rosetas nos pés e faziam aquele barulho: crec, crec, crec. Meu pai olhou bem. Já pensou eu com luva branca, tailleur de linho, me achando aquela dona num lugar desses. Meu pai olhou para mim e falou assim: "Filha, se quiser ficar você fica, se não quiser vamos embora”. (CARVALHEIRO, 2013).

Esse choque entre as realidades dos centros mais desenvolvidos do Estado onde as normalistas nasciam e se formavam, com a situação de colonização recente do extremo oeste paulista, era algo que as autoridades da educação já haviam notado pelo menos desde a década de 1930:

A professora que despachamos para a zona rural não é, na quasi totalidade dos casos, a que convem a essa zona. Seria talvez excellente para a cidade, onde cresceu e se educou. Vae para a roça coagida pela necessidade. Algumas se transformam em verdadeiras heroínas, pois, luctando embora com as maiores difficuldades, realizam a sua missão educativa. (SÃO PAULO, 1936, p. 182-183).

Maria Therezinha viveu primeiramente um conflito em relação à escolha da profissão que seguiria, haja vista que desejava estudar medicina, mas sua mãe fez com que ela ingressasse na escola normal. Não tendo conseguido ingressar no curso de medicina, a professora enfrentava outro desafio naquele início da década de 1950: 0 começo da vida profissional no magistério.

E aí, vamos trabalhar, né? Eu me sentia humilhada de ser professora! Eu tinha e ainda tenho vocação para fazer isso (referindo-se à medicina). Eu trato de minhas cachorras, faço curativo, aplico injeção. Aqui por perto quando a criançada se machucava, eles diziam: "Manda para a Therezinha!" Eu tinha vocação para isso, mas fui cortada.

A minha família é uma família de mulheres muito persistentes, quando marcam um caminho para seguir é aquele e não tem volta. Então eu fiquei. (CARVALHEIRO, 2013, grifos nossos).

É possível pensar este trecho do depoimento de Maria Therezinha dentro da 
História Cultural ${ }^{13}$, à luz das categorias de representação e de apropriação de Chartier (2002). Isto porque, existia uma representação sobre um suposto "[...] caráter essencialmente feminino atribuído ao papel da professora". (GOUVEIA, 1965, p. 45). Gouveia (1965) ${ }^{14}$ aponta ainda que "este seria um papel muito semelhante ao papel que sempre se atribuiu à mulher - a professora trabalha com crianças e em ambiente onde não se expõe ao contato com estranhos (não familiares) do sexo oposto". (GOUVEIA, 1965, p. 45). Maria Therezinha, contrariando este ideário que predestinava as mulheres à atividade docente com a primeira infância, não acreditava que aquela deveria ser a sua profissão, considerando-a, a princípio, uma humilhação.

Somente depois, a professora começou a aceitar o trabalho no magistério. Entretanto, Maria Therezinha não se apropriou da representação vigente sobre as mulheres e o magistério, e preferiu atribuir a sua decisão de prosseguir na docência a persistência presente nas mulheres de sua família. E mesmo tendo lecionado durante toda a sua vida profissional, mais de sessenta anos após ter chegado à Presidente Venceslau, ainda acreditava em sua inclinação para a medicina (Eu tinha vocação para isso, mas fui cortada).

Ao contrário de Maria Therezinha, Maria de Lourdes Fontana Pardo demonstrou que optou desde o início pela carreira docente: "Eu gostava de estudar e se eu tivesse que voltar, eu seria professora. (PARDO, 2013). As primeiras experiências desta docente se deram ainda durante seu período como normalista: "Como eu lecionei três anos em cursos de alfabetização de adultos, no quadro voluntário, enquanto eu cursava o magistério entre 1952 e 1953, e em 1954, e como eu tinha bastante pontos, em outubro de 1955 eu ingressei no magistério estadual". (PARDO, 2013).

Após ingressar no magistério estadual em meados da década de 1950, Maria de L. F. Pardo também passou um tempo lecionando na zona rural de Presidente Bernardes:

$\mathrm{Na}$ Vila Nova havia a escola Isolada na qual eu lecionei durante seis meses e depois eu fui para a escola do Quilômetro Cinco. [...] eu lecionava nas escolas isoladas nos primeiros anos. Primeiro eu fui na Escola Isolada do Quilômetro Cinco, lá eu fiquei por cinco anos, em 1960 eu vim para o Grupo Escolar Alfredo Westin Jr. (PARDO, 2013).

A docente revelou ainda que percebia a existência de uma aura de respeitabilidade da população rural em relação às professoras: "Quem lecionava em escola rural, o pessoal do sítio, nossa! Veneravam o professor! Para eles eram como se fossem reis que estavam ali!" (PARDO, 2013).

Entretanto, transparece no relato da docente que esta representação que ela havia percebido entre as comunidades que a acolhiam nos sítios, não era compartilhada pelas

\footnotetext{
${ }^{13}$ Roger Chartier (2002), delimita qual seria o principal objeto da História Cultural: "A historia cultural, tal como a entendemos, tem por principal objeto identificar o modo como em diferentes lugares e momentos uma determinada realidade social é construída, pensada, dada a ler. Uma tarefa deste tipo supõe vários caminhos. O primeiro diz respeito às classificações, divisões e delimitações que organizam a apreensão do mundo social como categorias fundamentais de percepção e de apreciação do real. Variáveis consoante as classes sociais ou os meios intelectuais, são produzidas pelas disposições estáveis e partilhadas, próprias do grupo. São estes esquemas intelectuais incorporados que criam as figuras graças as quais o presente pode adquirir sentido, o outro tornar-se inteligível e o espaço ser decifrado. (CHARTIER, 2002, p. 16-17).

${ }^{14}$ Aparecida Joly Gouveia, em sua obra Professoras de amanhã: um estudo de escolha ocupacional, realizou no ano de 1960, uma pesquisa com 1448 normalistas em 23 Escolas Normais de São Paulo e Minas Gerais buscando analisar a escolha vocacional das mulheres frente a uma sociedade que urbanizava e, por isso, alterava a inserção destas.
} 
autoridades da educação. Isto porque, ao ser questionada se já havia sido convidada a representar a escola que trabalhava, Maria de L. F. Pardo afirmou que essa situação ocorreu duas vezes, ambas em São Paulo. Na primeira vez participou de um curso sobre a Revolução de 1932 e na outra ocasião, frequentou uma formação cujo posicionamento das ministrantes lhe desagradou:

Era a Lucília Bechara e a irmã dela que deram os cursos, uma professora de matemática outra de português, mas eu não gostei nenhum pouco porque elas não eram professoras que haviam trabalhado no interior, não conheciam a realidade. Aí elas começaram a falar um negócio e eu fui lá falar com ela: "Mas como eu posso fazer isso se eu - naquele tempo eu estava na escola isolada - se eu tenho primeira, segunda e terceira séries [juntas]? Eu não posso agir desta forma". Aí ela disse: "Não, mas isso não é a nossa realidade!". Eu falei: "Não é a sua, mas é a minha!". E elas bateram daquele jeito do começo até o fim e a gente não podia falar nada porque eram elas quem decidiam.

Era uma falta de consideração com o povo da roça! Eles pensavam: "É da roça, deixe pra lá!". Agora, eles vivem no gabinete e tinha professor que ia à cavalo para a escola. A Doca, a Cida Francana, a Cida Magrini iam à cavalo. Eu era mais chique, eu ia de charrete. (Risos) O carro não tem todos os cavalos!? Eu ia com um! (Risos). (PARDO, 2013).

Esse afastamento entre o mundo urbano e o rural, ou entre as formas de ensinar no campo e na cidade, notado por Maria de L. F. Prado era um problema antigo. Vinte anos antes de a docente iniciar a sua carreira no magistério, Almeida Júnior já afirmava: "querer que a professora sosinha, sem assistência material e moral, puxe o bairro para frente, é pedir demais á pobre moça". (SÃO PAULO, 1936, p. 195). Nesse mesmo Anuário, o Diretor do Ensino denunciava que "Na escola rural, a professora trabalha só. O inspetor vem de longe em longe, e tem pressa. Não ha quem aprecie o esforço e estimule". (SÃO PAULO, 1936, p. 198). Por isso, não era infundada a crítica e a sensação de abandono relatada por Maria de L. F. Prado, porque a situação pela qual passava não era novidade.

Porém, como já mencionado, essas primeiras experiências das professoras nas escolas rurais do extremo oeste paulista, serviriam para mostrar às docentes que as dificuldades não se restringiriam ao campo e que seria necessário lançar mão de algumas estratégias para poderem realizar seu trabalho.

\section{Considerações finais}

Como visto, as docentes iniciaram a sua atividade profissional enfrentando dificuldades de toda a ordem, seja em relação aos aspectos materiais ou às concepções de gênero.

Primeiramente, sofreram o choque de se verem diante de uma realidade paupérrima e muitas vezes desprovida de uma estrutura básica, tal como as zonas rurais apresentavam no período estudado. Boa parte das docentes eram provenientes de cidades maiores, mais antigas e desenvolvidas, recém-saídas das escolas normais das zonas urbanas, e tiveram de ter "tempera fórte" para lidar com os contrastes que aquele contexto apresentava.

Por fim, entre avanços e recuos, essas professoras permaneceram trabalhando e sendo importantes artífices da cultura escolar nos grupos escolares de Presidente Bernardes e de Presidente Venceslau. 


\section{Referências}

ALMEIDA, Jane Soares de. Mulher e educação: a paixão pelo possível. São Paulo: Editora Unesp, 1998.

AMADO, Janaína. Região, sertão, nação. Estudos históricos, Rio de Janeiro, v. 8, n. 15, p. $145-151,1995$.

BOURDIEU, Pierre. A dominação masculina. Trad. de Maria Helena Kühner. 10 ed. Rio de Janeiro: Bertrand Brasil, 2011.

CHARTIER, Roger. A História Cultural: entre práticas e representações. Trad. de Maria Manuela Galhardo. Lisboa: Difel, 2002.

DIAS, Romualdo. Imagens de ordem: a doutrina católica sobre autoridade no Brasil (1922-1933). São Paulo: Editora Unesp, 1996.

D'INCAO, Arthuzina de Oliveira. Fragmentos. São Paulo: Editora Soma, 1982.

D'INCAO, Maria Angela; NASCIMENTO, Luís Eduardo Passos. Presidente Wenceslau: uma região, a cidade e sua gente. Presidente Venceslau: Letras à Margem, 2005.

ERBELLA, Inocêncio. Rabiscos históricos de Presidente Venceslau. Presidente Venceslau: Editora Artes Gráficas Pedrali, 2006.

GOUVEIA, Aparecida Joly. Professoras de amanhã: um estudo de escolha ocupacional. Rio de Janeiro: Centro Brasileiro de Pesquisas Educacionais, Instituto Nacional de Estudos Pedagógicos, Ministério da Educação e Cultura, Brasil, 1965.

JULIA, Dominique. A cultura como objeto histórico. Revista Brasileira de História da Educação, Campinas, n. 1, p. 9-43, 2001.

LOURO, Guacira Lopes. Gênero, sexualidade e educação: uma perspectiva pósestruturalista. Petrópolis, RJ: Vozes, 1997.

MARCÍLIO, Maria Luiza. História da escola em São Paulo e no Brasil. São Paulo: Imprensa Oficial do Estado de São Paulo, Instituto Fernand Braudel, 2005.

MARIANO, Jorge Luís Mazzeo. As influências do trabalho docente feminino na cultura escolar do extremo oeste paulista (1932-1960). 2016. 405 f. Tese (Doutorado em Educação) - Faculdade de Ciências e Tecnologia, Universidade Estadual Paulista/Unesp, Presidente Prudente, 2016.

MONBEIG, Pierre. Pioneiros e fazendeiros de São Paulo. Trad. de Ary França e Raul Andrade e Silva. São Paulo: Editora Hucitec/Editora Polis, 1984.

MORAES, Agnes lara Domingos. Ensino primário tipicamente rural no Estado de São Paulo: um estudo sobre as granjas escolares, os grupos escolares rurais e as escolas típicas rurais (1933-1968). 2014. 183 f. Dissertação (Mestrado em Educação) - Faculdade de Filosofia e Ciências, Universidade Estadual Paulista/Unesp, Marília, 2014.

PINTO, Céli Regina Jardim. Uma história do feminismo no Brasil. São Paulo:

Fundação Perseu Abramo, 2003. (Coleção História do Povo Brasileiro).

RIBEIRO, Arilda Ines Miranda. Mulheres educadas na Colônia. In: LOPES, Eliane Marta Teixeira; FILHO, Luciano Mandes de Faria; VEIGA, Cynthia Greive (Orgs.). 500 anos de educação no Brasil. 3 ed. Belo Horizonte: Autêntica, 2007, p. 79-94.

ROMANELLO, Jorge Luiz. Imagens e visões do paraíso no oeste paulista: um estudo do imaginário regional. 1998. 168 f. Dissertação (Mestrado em História) - Programa de Pós-Graduação em História, Universidade Estadual Paulista/Unesp, Assis, 1998.

SOUZA, Rosa Fátima de. Um itinerário de pesquisa sobre a cultura escolar. In: CUNHA, 
Marcus Vinicius da (Org.). Ideário e imagens da educação escolar. Campinas: Autores Associados; Araraquara: Programa de Pós-Graduação em Educação Escolar da Faculdade de Ciências e Letras da Unesp, 2000. p. 3-28.

THOMPSON, Paul. A voz do passado: história oral. Trad. de Lólio Lourenço de Oliveira. Rio de Janeiro: Paz e Terra, 1992.

\section{Documentos}

RELATÓRIO PRESIDENTE PRUDENTE. Relatório de 1935 da Inspetoria Sanitaria de Presidente Prudente. Apresentado ao D. Delegado Regional do Ensino Senhor Professor Vitor Miguel Romano pelo Inspetor Sanitario Dr. Alfredo Zagottis. 1935. 157 p. (E 07039 - Datilografado)

RELATÓRIO PRESIDENTE PRUDENTE. Relatório de 1940 da Delegacia Regional do Ensino de Presidente Prudente. Apresentado ao D. D. Diretor Geral do Departamento de Educação Execelentissimo Senhor Doutor Antenor Romano Barreto pelo Delegado Regional do Ensino Miguel Omar Barreto. 1941. 111 p. (E 07038 - Datilografado) SÃO PAULO (Estado). Annuario do Ensino do Estado de São Paulo. São Paulo: Diretoria do Ensino, 1936/37, 732 p.

\section{Jornais}

CAMARGO, Rocha. O clero protesta pela palavra de S. Excia. Revma. D. José Maurício da Rocha, contra o uso, pelas mulheres, de nossas venerandas calças! A Tribuna, Presidente Venceslau, p. 2, 29 ago. 1954.

\section{Fontes orais}

CARVALHEIRO, M. T. de G. P.; GONÇALVES, M. de N. M. Maria Therezinha de Granville Ponce Carvalheiro: depoimento [mai. 2013]. Entrevistador: Jorge Luís Mazzeo Mariano. Presidente Venceslau: 2013. 1 arquivo .mp3 (4 h 12 min 18 seg). A entrevista encontra-se transcrita em mídia digital no arquivo pessoal do pesquisador.

ESTRELA, M. P. Maura Pereira Estrela: depoimento [mai. 2013]. Entrevistador: Jorge Luís Mazzeo Mariano. Presidente Venceslau: 2013. 1 arquivo .mp3 (3 hrs 48 min 48 seg). A entrevista encontra-se transcrita em mídia digital no arquivo pessoal do pesquisador.

MORAD, W. P. Wanda Pereira Morad: depoimento [abr. 2013]. Entrevistador: Jorge Luís Mazzeo Mariano. Presidente Venceslau: 2013. 1 arquivo .mp3 (2 hrs 10 min 28 seg). A entrevista encontra-se transcrita em mídia digital no arquivo pessoal do pesquisador.

OLYVEIRA, M. A. L. de. Maria Apparecida Lotto de Olyveira: depoimento [jun. 2013]. Entrevistador: Jorge Luís Mazzeo Mariano. Presidente Bernardes: 2013. 1 arquivo .mp3 (3 h $47 \mathrm{~min} 21 \mathrm{seg}$ ). A entrevista encontra-se transcrita em mídia digital no arquivo pessoal do pesquisador.

PARDO, M. de L. F. Maria de Lourdes Fontana Pardo: depoimento [set. 2013]. Entrevistador: Jorge Luís Mazzeo Mariano. Presidente Bernardes: 2013. 1 arquivo .mp3 (1 h $55 \mathrm{~min} 01 \mathrm{seg}$ ). A entrevista encontra-se transcrita em mídia digital no arquivo pessoal do pesquisador.

VIEIRA, T. de C. Thereza de Camargo Vieira: depoimento [jul. 2013]. Entrevistador: Jorge Luís Mazzeo Mariano. Presidente Bernardes: 2013. 1 arquivo .mp3 (2 hrs 14 min 04 seg). A entrevista encontra-se transcrita em mídia digital no arquivo pessoal do pesquisador. 
JORGE LUÍS MAZZEO MARIANO realiza estágio de Pós-doutorado na Universidade do Oeste Paulista (Unoeste), como bolsista PNPD/Capes. Doutor em Educação pela Universidade Estadual Paulista (Unesp) - Campus de Presidente Prudente.

Endereço: Rodovia Raposo Tavares - Km 572, 19026-310, Presidente Prudente/SP, Brasil.

E-mail: jorgemariano86@yahoo.com.br

ARILDA INES MIRANDA RIBEIRO é professora do Programa de Pós-Graduação em Educação da Universidade Estadual Paulista (Unesp). Livre Docente pela Universidade Estadual Paulista (Unesp) - Campus de Presidente Prudente.

Endereço: Rua Roberto Simonsen, 305 - Centro Educacional, 19060-900, Presidente Prudente/SP, Brasil.

E-mail: arilda@fct.unesp.br

Recebido em 26 de março de 2017.

Aceito em 20 de abril de 2017. 